\title{
Erratum to: Does visual short-term memory have a high-capacity stage?
}

\author{
Michi Matsukura $^{1}$ • Andrew Hollingworth ${ }^{1}$
}

Published online: 24 January 2017

(C) Psychonomic Society, Inc. 2017

\section{Erratum to: Psychon Bull Rev}

DOI 10.3758/s13423-011-0153-2

Erratum to Matsukura, M., \& Hollingworth, A. (2011). Does visual short-term memory have a high-capacity stage? Psychonomic Bulletin \& Review, 18, 1098-1104.

p. 1103. Results and discussion: $F(1,9)$ should be $F(9,9)$. The $F$ and $p$ values are from the within-subjects one-way ANOVA with $F(9,9)$.

p. 1100. "The bar stimuli $\left(1.93^{\circ} \times 0.21^{\circ}\right)$ were presented in one of four orientations (vertical, horizontal, $45^{\circ}$, and $45^{\circ}$ )." The second $45^{\circ}$ should be " $-45^{\circ}$," which is equivalent to $135^{\circ}$. p. 1102. Fig. 3a: On the $x$-axis above Exp. 2, "Neutra" should be "Neutral."

The online version of the original article can be found at http://

dx.doi.org/10.3758/s13423-011-0153-2.

Michi Matsukura

michi-matsukura@uiowa.edu

Andrew Hollingworth

andrew-hollingworth@uiowa.edu

1 Department of Psychology, University of Iowa, 11 Seashore Hall E, Iowa City, IA 52242, USA 